Revista Mídia e Cotidiano

Artigo Seção Livre

Volume 11, Número 1, abril de 2017

Submetido em: 10/04/2017

Aprovado em: 30/04/2017

\title{
HOMOSSEXUALIDADE E ALTERIDADE: uma análise bakhtiniana das Paradas Gays
}

\section{HOMOSEXUALITY AND ALTERITY: a bakhtinian analysis of Gay Parades}

\author{
João Paulo MALERBA ${ }^{1}$
}

Resumo: $\mathrm{O}$ artigo analisa a condição homossexual e as Paradas Gays à luz do conceitual bakhtiniano. Parte-se de um breve panorama sobre a situação dos homossexuais no mundo, na sociedade e na mídia, em que se verifica a negação de suas singularidades no constituinte jogo ontológico da alteridade. Em seguida, o artigo discute as Paradas Gays enquanto atos de enunciação coletiva e coloca em questão se seu tom festivo anula seu caráter de ato político. A partir do conceito de carnavalização em Bakhtin, conclui-se vir precisamente daí sua força libertária, libertadora e emancipadora.

Palavras-chave: Parada gay; Bakhtin; Carnavalização.

Abstract: The article analyzes the homosexual condition and the Gay Parades in the light of Bakhtin's theories. A brief overview of the situation of homosexuals worldwide, in society and represented within the media, reveals the negation of their singularities in the constituent ontological game of otherness. The article goes to discuss the Gay Parades as acts of collective enunciation and calls into question whether their festive tone nullifies their character as a political act. From the concept of carnivalization in Bakhtin, the paper concludes that it is precisely from this that it derives its liberating, libertarian and emancipatory force.

Keywords: Gay parade; Bakhtin; Carnavalization.

\footnotetext{
1 Professor e jornalista, é doutor em Comunicação e Cultura pela Escola de Comunicação da Universidade Federal do Rio de Janeiro (ECO/UFRJ). É pesquisador no Laboratório de Estudos em Comunicação Comunitária (LECC/UFRJ) e membro da Associação Mundial das Rádios Comunitárias (AMARC Brasil). E-mail: joaopaulomalerbaarrobagmail.com.
} 


\section{Introdução: ser homossexual ${ }^{2}$, locus simbólico e social}

"Tomar consciência da vida é tomar consciência da fé e da esperança, da insatisfação e do possivel" Mikhail Bakhtin

Madrugada do dia 13 de julho de 2007. O ator, dançarino e coreógrafo José Hilton da Silva Valentim, de 42 anos, é brutalmente assassinado numa das ruas da cidade de Caruaru, em Pernambuco. De acordo com a polícia local, havia indícios de que a morte tenha sido causada por mais de uma pessoa. Ao lado do corpo despido, foram encontrados dois preservativos usados. Nenhum objeto de valor foi roubado. Era o segundo caso fatal de violência contra homossexuais em Caruaru naquele ano: em meados de junho, um travesti identificado somente pelo nome de Cíntia, de 30 anos, fora assassinado no local onde fazia programas ${ }^{3}$.

Fevereiro de 2006, Portugal. A transexual brasileira Gisberta Salce Junior, de 46 anos, foi torturada e violentada sexualmente durante três dias por treze adolescentes. Em seguida, a vítima foi lançada num poço para morrer por afogamento. Meses depois, o homicídio de Gisberta foi desculpabilizado pelo sistema judicial português como "uma brincadeira que correu mal" 4 .

Uganda, 1999. Cristina e mais quatro defensores dos direitos humanos dos homossexuais são detidos durante uma reunião em que articulavam suas próximas ações em prol da condição dos gays e lésbicas do país. Os militantes foram levados para locais diferentes, onde foram brutalmente agredidos e torturados. Num centro de detenção secreto de Uganda, Cristina foi violentada diversas vezes ${ }^{5}$.

Todo ano, em todo o mundo, a intolerância contra os homossexuais extingue a luz e silencia a voz de outros tantos Josés, Gisbertas, Cíntias e Cristinas. Os ecos dessa

\footnotetext{
2 Por motivos puramente estilísticos, o termo "homossexual" será utilizado para designar um grupo maior: gays, lésbicas, transexuais, bissexuais e travestis.

Disponível

em http://www.folhape.com.br/folhape/materia.asp?data edicao=17/07/2007\&mat=51713. $\quad$ Acesso $\quad \mathrm{em}$ 24/07/2007.

Disponível em http://www.ilga.org/news results.asp?languageid=5\&filecategory=408fileid=899. Acesso em 25/07/2007.

$5 \quad$ Revista Fórum, nº 3, 2002. A estupidez da intolerância por Rose Silva e Luciana Ackermann, pág. 12.
} 
violência sistemática, além de contribuir para que gays e lésbicas sejam lançados no escuro e na mudez do medo, acabam por reprimir inúmeras outras subjetividades. Vítimas indiretas da homofobia, amordaçados pelo receio do estigma e do preconceito, psicologicamente afligidos por tabus e preceitos religiosos, mesmo as pessoas não homossexuais são simbolicamente desencorajadas a viver plenamente sua sexualidade. Se o insulto do homofóbico fere como um projétil a autoestima dos homossexuais, seus estilhaços reprimem toda a sociedade, afetam pessoas de toda e qualquer vivência da sexualidade.

Em muitos países, os crimes contra indivíduos devido à sua orientação sexual são promovidos pelo próprio Estado. Apesar dos recentes e importantes avanços conquistados em todo o mundo em favor dos direitos dos homossexuais, em países como Afeganistão, Somália, Uganda, Arábia Saudita, Iêmen, Emirados Árabes, Irã, Sudão, Mauritânia, Nigéria e Paquistão, os casos de prática homossexual são punidos com pena de morte; já em Serra Leoa, Tanzânia, Barbados, Paquistão e Mianmar, a pena da prisão perpétua pode ser aplicada. No total, em 82 países a homossexualidade (principalmente masculina) é ilegal $^{6}$. Ou seja, em mais da metade dos países do globo, ser homossexual é considerado crime, uma ameaça à ordem social. A tais brados, somam-se as condenações de diversas religiões quanto a livre orientação sexual.

Com ou sem a legitimação do poder público, essa homodiscriminação segue alimentando-se dos estereótipos que relacionam a representação do homossexual a ideias de promiscuidade, vulgaridade, futilidade, vaidade, fragilidade, extravagância, frivolidade. Seguindo a dinâmica própria dos signos sociais, esses estereótipos ao mesmo tempo em que refletem, também reforçam a imagem que os diferentes atores constroem dos bissexuais, gays e lésbicas, travestis e transexuais (e, consequentemente, a percepção que estes erigem de si mesmos). A forma mais comum de circulação dos estigmas é também a mais perversa: eles comumente deslizam por entre as diferentes esferas da sociedade através de "inofensivas" brincadeiras e piadas cujos personagens são homossexuais caricaturizados. O caráter aparentemente não intencional de sua emissão

6 Dados obtidos em https://pt.wikipedia.org/wiki/Legislação sobre pessoas LGBT no mundo. Acesso em 04/04/2017. 
esconde o perigo inerente ao deboche, à chacota, ao desdém. Como afirma Hélio Silva, em seu trabalho etnográfico com travestis cariocas: "talvez possamos estabelecer uma linha de comunicação entre o risinho no canto direito da boca do intelectual macho (ou do gay respeitável) com a bala que fere o seio esquerdo do travesti. O risinho cria na verdade a ambiência que neutraliza a decisão de apertar o gatilho" (SILVA, 1993, p. 16). O outro tornado risível não é passível de ser problematizado: a caricatura anula sua subjetividade. Esvazia-se a alteridade da sua maior fonte de valor: o lugar único e absolutamente singular que cada qual ocupa no mundo. Tornado objeto de escárnio, o outro se tipifica; tipificado, perde sua unicidade; reduzido a mais um entre tantos, fica mais fácil aceitar sua extinção. O problema não está na piada e sim no que ela naturaliza.

A representação que os meios de comunicação frequentemente fazem do homossexual oferece pistas sobre a condição deste na sociedade. Poucas vezes o gay é retratado na mídia de uma forma não extraordinária ${ }^{7}$. A invisibilidade torna-se marca, com sua presença sendo autorizada normalmente em espaços específicos, como programas humorísticos e de auditório, onde desfilam uma sucessão de personagens estereotipados. Essa representação equivocada e os parcos referenciais positivos, além de influenciarem negativamente o imaginário social acerca da diversidade sexual, também dificultam a própria autoaceitação quando da descoberta individual da não heterossexualidade. O jornalista e assessor de comunicação do Movimento Gay de Minas, Jorge Júnior, conta que quando se descobriu gay, viveu um dos períodos mais difíceis de sua vida: "Não possuía nenhuma referência positiva das homossexualidades. Como só

\footnotetext{
É importante registrar que, recentemente, os meios de comunicação têm tido um cuidado maior quanto à representação dos homossexuais em seus produtos culturais. Até mesmo algumas telenovelas de grande audiência passaram a problematizar relações homoafetivas em suas histórias. Apesar de limitadas a uma representação da homossexualidade clean e recatada, aceita pelo público, percebe-se um deslocamento do estereótipo gay em direção a um aprofundamento nos personagens. Em grande parte, tal mudança pode ser atribuída à vigilância e pressão do próprio movimento gay organizado. No final de 2003, o programa veiculado pela Rede TV!, "Tarde Quente”, liderado pelo então apresentador João Kleber, foi tirado do ar pela Justiça Federal acusado de promover a homofobia e desrespeitar os direitos humanos. A ação foi resultado de uma representação conjunta feita no Ministério Público Federal por seis ONGs que defendem os direitos humanos.
} 
haviam me mostrado visões estereotipadas dessas vivências, achava que seria errado gostar de outro homem" 8 .

Se a discriminação contra homossexuais nem sempre culmina em eventos trágicos, a agressão simbólica da não representatividade social é cotidiana. Formal ou informalmente impedida de viver suas histórias nos espaços comuns e motivados por uma necessidade de reconhecimento mútuo, grande parte dos homossexuais encontra a proteção e a aceitação (imprescindíveis para qualquer vida) em graus maiores ou menores de guetificação. O movimento é duplo: externamente, uma força de repulsão social; internamente, um quase instinto de autopreservação. A não abertura é recíproca. A perda é generalizada. Erguem-se barreiras ante um personagem indispensável para a construção do ser: o outro.

\section{Eu e o outro: singularidades complementares}

Mikhail Mikhailovich Bakhtin (1895-1975) foi um pensador russo da linguagem cujos conceitos, formulados no início do século XX, apresentam-se de uma atualidade surpreendente. Para o complexo cenário contemporâneo de poder, em que múltiplos e diversos atores solicitam a possibilidade de serem ouvidos, o pensamento bakhtiniano oferece a abertura ao diálogo 9 . O próprio Bakhtin formulou suas ideias a partir de uma troca permanente: o famoso círculo bakhtiniano reunia figuras das mais diversas áreas do conhecimento por meio de encontros regulares, com o intuito de construir conceitos através do diálogo e do conflito de ideias.

O próprio ser para Bakhtin só existe na relação. Para o autor, o ser não é substância, nem tem uma essência pré-dada. Caracterizado por um não acabamento inerente, o ser é puro devir. A própria experiência do estar no mundo está inextricavelmente marcada por uma incompletude essencial e é na relação com o outro que o ser vai se constituindo. Melhor explicando: o lugar absolutamente único que ocupo no mundo, minha posição

\footnotetext{
8 Disponível em http://www.mgm.org.br/portal/modules.php?name=News\& file=article\&sid=242. Acesso em 26/07/2007.

Apesar de seus objetos de estudo serem a literatura e a estética, a dimensão ontológica perpassa todo o pensamento de Bakhtin, formando um todo orgânico conceitual de preocupação eminentemente ética, ligado a práxis.
} 
singular no espaço e no tempo, define e limita meu olhar. Tal posição implicará num eterno excesso e numa eterna falta em relação ao outro:

quando contemplo um homem situado fora de mim (...) sempre verei e saberei algo que ele próprio, na posição que ocupa, e que o situa fora de mim e à minha frente não pode ver (...) esse excedente constante da minha visão e do meu conhecimento a respeito do outro, é condicionado pelo lugar que sou o único a ocupar no mundo (BAKHTIN, 1992, p. 43).

Da mesma forma, minha existência é marcada por uma falta constante: de onde estou não posso me ver de forma acabada, sempre precisarei do excedente da visão do outro para completar minha autoimagem; necessito da sua cosmovisão, definida pelo lugar no mundo que só ele e ninguém mais pode ocupar. Daí a importância da relação com o outro para a construção de si. Por isso, o ser não se basta e somente poderá inteiramente existir na troca, na relação. A existência estará inevitavelmente balizada por esse paradoxo constituinte de falta e excesso quanto à alteridade.

A possibilidade de acabamento será sempre um movimento exotópico em direção ao outro: o ponto de vista externo que constrói minha visão interna. "Num mundo que me é exterior, o outro se oferece por inteiro à minha visão (...) a cada instante vivo indistintamente todas as fronteiras do outro" (BAKHTIN, 1992, p. 55). Somente o outro, passível de acabamento, poderá ser minha fonte axiológica: "não posso ser o autor do meu próprio valor assim como não posso pegar-me pelos cabelos e içar-me” (id., p. 73). Meus atos - no tempo, no espaço, no sentido - são desenvolvidos todos no meu horizonte e "esse horizonte não pode fechar-se e abarcar um eu tranquilizado e constituir um ambiente de valores para mim" (id., p. 202, grifo meu). Essa carga axiológica somente se apresentará de forma pronta na contemplação de um ser que não coincida comigo. Tudo o que dá valor ao dado do mundo está vinculado ao outro.

Se a possibilidade de acabamento do outro em seu plano de valor se oferece como uma dádiva, a mim caberá a abertura diante da experiência da existência. Se no lago da alteridade sou capaz de vislumbrar seu fundo axiológico decantado, do rio da minha existência apenas posso viver meu devir. Minha possibilidade de ação estará determinada mesmo por esse não acabamento essencial: "para viver, devo estar inacabado, aberto para mim mesmo - pelo menos no que constitui o essencial da minha vida -, devo ser para 
mim mesmo um valor ainda porvir, devo não coincidir com minha própria atualidade" (id., p. 33). E esse será o motor da minha existência. O acabamento ou coincidência com seu próprio valor seria a morte do sujeito.

O ser enquanto processo vai se construindo nesse movimento para fora de si, na tensão entre abertura e acabamento, na relação entre o eu (abertura) e o outro (possibilidade de acabamento).

Porém, é importante ressaltar que, para Bakhtin, eu e o outro representam experiências completamente distintas e assim o devem permanecer.

Que vantagem teria eu que o outro se funda comigo? Ele (...) somente reproduzirá em si mesmo o que em minha vida continua sem solução; é preferível que ele permaneça fora de mim, pois é a partir de sua posição que pode ver e saber o que, a partir da minha posição, não posso nem ver nem saber, sendo assim que ele poderá enriquecer o acontecimento da minha vida" (BAKHTIN, 1992, p. 102, grifo meu).

Pois, "a solução não é imanente à vida, é-lhe concedida como uma dádiva que emana da atividade do outro, do outro que vai ao encontro dela" (id., p. 95). É no exercício da exotopia que se dá a produtividade do ato. O movimento exterior em direção ao outro não deve significar nossa coincidência: "devo colocar-me em seu lugar, e depois, de volta ao meu lugar, contemplar seu horizonte com tudo o que se descobre do lugar que ocupo fora dele" (id., p. 45).

Bakhtin ressalta que ambos, eu e o outro, "evoluímos em níveis (planos) distintos da visão e do juízo do valor" (id., p. 76). Esse dado, ao mesmo tempo em que é a verdadeira possibilidade de emancipação humana (a possibilidade de solução para a minha vida na atitude em relação ao outro), é também uma possível - e provável - fonte de conflitos.

E, se não podemos desconsiderar a dimensão conflitiva da interação com o outro, cabe-nos refletir de que forma é possível dela tirar maior proveito para a solução de nossa existência. Ainda um trecho do livro Estética da Criação Verbal nos oferece diretrizes:

O essencial para nós aqui não deixa a menor dúvida: viver o outro de modo real, concreto, valorizado, no interior do todo fechado da minha própria vida, se assinala por essa ambivalência [de planos de valores distintos entre eu e o outro] (...), e se quero operar uma transposição que nos coloque, eu e o outro, 
num único e mesmo nível, devo, em meus valores perceber-me como outro entre outros (BAKHTIN, 1992, p. 76, grifos meus).

Viver essa ambivalência axiológica de forma plena significa adotar uma horizontalidade em relação ao outro: colocar-nos no mesmo nível para que a troca seja então efetiva. Para tal, devo "perceber-me como outro entre outros", devo negar a presunção da autorreferência e ter em mente que sou evento tanto quanto qualquer outro ser.

Ao esvaziar e reduzir o outro a uma carcaça estereotipada, perde-se a chance de que ele se apresente a nós como um todo pleno de valores capaz de tomar parte no enriquecimento da percepção que temos de nós e do mundo. A própria verdade para Bakhtin é polissêmica: será tão mais completa quão mais plural for. Por estar preso a um espaço-tempo e, dessa forma, marcado por uma falta essencial, sozinho o ser não pode ser fonte de verdade: esta só pode existir na interação entre os seres, na multiplicidade de versões e verdades. Mais próximo estarei da verdade quão mais aberto estiver à troca, quão mais disposto estiver a dialogar com outras cosmovisões. Se anulo o outro, desprezo a oportunidade de acrescentar à minha esfera de sentidos seu campo visual-semiótico absolutamente singular. Desprezo o quinhão de verdade que ele, e somente ele, possui por conta do lugar da existência que ele, e somente ele, ocupa.

\section{Parada Gay: enunciação coletiva}

A situação de discriminação ${ }^{10}$, estigmatização, não reconhecimento de direitos e a consequente guetificação de lésbicas, transexuais, gays, bissexuais e travestis impõe barreiras que os impedem de negociar de forma igualitária os sentidos que circulam na sociedade. Quando o Estado, enquanto corpo cristalizado dos acordos sociais, não estende determinados direitos a uma parcela da população devido a sua orientação sexual, está favorecendo um processo de invisibilização desses atores que tem influenciado de forma cada vez mais significativa a cultura e as instituições sociais.

\footnotetext{
10 Uma pesquisa realizada com os participantes da $10^{\circ}$ Parada do Orgulho Gay de São Paulo e divulgada no livro Sexualidade, cidadania e homofobia : pesquisa 10 ${ }^{\text {a }}$ Parada do Orgulho GLBT de São Paulo - 2006 revelou que 67\% (dois em cada três) entrevistados já foram vítimas de algum tipo de discriminação por sua orientação sexual. A mesma pesquisa mostra que $59 \%$ já foi vítima de agressão física, verbal, violência sexual ou chantagem por conta da sua homossexualidade.
} 


\section{míDiA

Há cerca de 50 anos é realizada em diversas cidades em todo o mundo a Parada GLBT ou Parada do Orgulho Gay. Considerados por muitos a expressão máxima dos movimentos sociais que lutam pelos direitos dos homossexuais (MACHADO \& PRADO, 2007, p. 2), as Paradas têm o objetivo de dar visibilidade à população homossexual e suas demandas, tanto de reconhecimento de direitos junto ao Estado, quanto de respeito à diversidade sexual frente à sociedade.

As Paradas começaram a ser organizadas no ano seguinte ao famoso evento do bar Stonewall, quando em 28 de junho de 1969 houve uma série de conflitos violentos entre policiais e a clientela gay do bairro nova-iorquino de Greenwich Village. Desde então temos visto a multiplicação desse tipo de evento que ocorre anualmente nas ruas das principais metrópoles do planeta. Primeiramente centenas, depois milhares e já hoje milhões de pessoas seguem em marcha festiva pelos caminhos urbanos mesclando cores, sons e imagens em celebração a diversidade sexual. Num primeiro momento, as Paradas tinham como principal intuito promover a visibilidade da população homossexual. De acordo com que iam se consolidando nas agendas sociais das cidades, passaram a ser utilizadas com a finalidade de "refletir sobre as demandas da comunidade [gay] e como forma de pressão política pelo reconhecimento e garantia efetiva dos direitos humanos do GLBT" ${ }^{11}$.

A busca é por uma sociedade plurivocal, utilizando mais um conceito bakhtiniano: polifonia. Metaforizando um termo tomado da linguagem musical, Bakhtin delineia a ideia de polifonia como a orquestração de várias vozes que necessariamente não se fundam numa única. Quando os brados dos participantes das Paradas solicitam uníssonos igualdade de direitos e respeito à diversidade sexual, o que também se está sendo agenciado é que na sociedade efetivamente haja uma "multiplicidade de vozes e consciências independentes e imiscíveis (...) [uma] polifonia de vozes plenivalentes [plenos de valor] (BAKHTIN, 1981, p. 4). Procura-se fugir exatamente da fusão forçada e mentirosa que impõe um "padrão de normalidade" quanto à sexualidade. E busca-se

\footnotetext{
11 Disponível em http://www.paradasp.org.br/modules/articles/article.php?id=6. Acesso em
} 25/07/2007 
que os diversos atores sociais tenham a possibilidade de agenciar seus valores em pé de igualdade com os demais.

Mas, como já foi dito mais acima, o requisito da plenivalência é a horizontalidade dos direitos de fala. Podemos considerar as Paradas GLBT como uma resposta pública de uma parcela população que busca a possibilidade de ser ouvida socialmente. Ou nas palavras de Frederico Viana Machado:

\begin{abstract}
As Paradas, como evento estratégico da visibilidade homossexual, interpelam os mecanismos sociais e institucionais de inferiorização social e discriminação sofrida pela população homossexual na sociedade (...), transformando a condição de vida desta população em tema público de discussão, debate e reflexão para o Estado e para a Sociedade Civil (MACHADO \& PRADO, 2007, p. 2).
\end{abstract}

Ao lançar na esfera pública o debate sobre a condição do homossexual, as Paradas do Orgulho Gay procuram deslocar o significado construído histórica e socialmente acerca de travestis, lésbicas, transexuais, gays e bissexuais; propõem-se a lançar novos signos sociais de forma a desarticular a carga axiológica pejorativa em torno do gay.

Para Bakthin qualquer significado é ideológico. "O domínio do ideológico coincide com o domínio dos signos: são mutuamente correspondentes” (BAKHTIN, 1987, p. 32). Uma das funções da ideologia é neutralizar determinados valores para toda a sociedade. "Na ideologia dominante estabelecida, o signo ideológico é sempre um pouco reacionário e tenta, por assim dizer, estabilizar o estágio anterior da corrente dialética da evolução social e valorizar a verdade de ontem como sendo válida hoje em dia" (id., p. 47). Porém, os signos são necessariamente interindividuais: diferentes subjetividades com interesses múltiplos se valem de tais signos. "Consequentemente, em todo signo ideológico confrontam-se índices de valor contraditório (...) Esta plurivalência social do signo é um traço da maior importância. É este entrecruzamento dos índices de valor que torna o signo vivo e móvel, capaz de evoluir (...) [e faz do domínio dos signos] uma arena para o confronto dos valores sociais vivos" (BAKHTIN, 1987, p.47). Os indivíduos esgarçam os sentidos pré-dados, pré-concebidos em busca de um novo consenso coletivo. E o espaço de luta dos atores sociais em torno dos significados será exatamente essa tensão proporcionada pela flexibilidade, pela instabilidade do signo. 
Podemos considerar o evento da Parada do Orgulho Gay como uma enunciação social coletiva. Durante o tempo de duração da marcha, as diversas singularidades lá presentes assumem uma unidade artificial a fim de dar visibilidade a uma demanda que as afeta coletivamente ${ }^{12}$. Bakhtin nos lembra que "qualquer que seja a enunciação considerada (...) ela, na sua totalidade, é socialmente dirigida (...) determinada da maneira mais imediata pelos participantes do ato de fala, explícitos ou implícitos" (BAKHTIN, 1987, p. 113). E, por ser socialmente dirigida, qualquer enunciação estará exposta a uma tensão própria: estando inevitavelmente ligada uma cadeia infinita de significados antecedentes e posteriores, ao mesmo tempo em que parcialmente nega, também afirma o dado social e historicamente construído, extrapolando seus limites anteriores com maior ou menor eficácia. Mesmo que o(s) sujeito(s) da enunciação tenha(m) a intenção explícita de negar totalmente o significado, isso não é possível, porque a enunciação será sempre feita num ambiente social cujos indivíduos terão seus pressupostos - e suas próprias intenções - que afetarão ativamente a compreensão. "Compreender a enunciação de outrem significa orientar-se em relação a ela (...) A cada palavra da enunciação que estamos em processo de compreender, fazemos corresponder uma série de palavras nossas, formando uma réplica" (BAKHTIN, 1987, p. 132) Na verdade, essa compreensão ativa será essencial para a vitalidade do signo. Dialogando com o que foi dito mais acima, na arena semântica social teremos sempre uma luta ideológica: de um lado, os participantes da enunciação com possíveis intenções de deslocamento do sentido e, de outro, a compreensão ativa dos demais participantes da situação de enunciação, munidos de seus pressupostos socialmente construídos e intenções próprias, que podem ou não estar em conflito com o deslocamento sugerido. O importante aqui não é a coincidência entre as intenções da enunciação e o resultado da compreensão, mas a possibilidade de ocorrência do diálogo e consequente abertura a negociação.

\footnotetext{
12 "A unidade artificial com que esse evento [a Parada Gay] é publicizado não pode ser entendida como homogeneização, pois a principal estratégia de emergência da diversidade de formas de vida social minoritárias no mundo público tem sido a luta por visibilidade social. É através da visibilidade que será possível a exposição pública de demandas sociais e a emergência de antagonismos." (MACHADO \& PRADO, 2007, p. 11)
} 
Festa ou ato político?

Com o passar dos anos, as Paradas foram se consolidando no calendário cultural das cidades. Para usar o exemplo da já considerada maior do mundo, a Parada Gay de São Paulo em somente dez anos de existência fez saltar dos cerca de 300 participantes em 1996 para quase três milhões em $2016^{13}$. A parada paulistana já é responsável por cerca de $10 \%$ do faturamento anual da cidade com turismo. Para organizar da Parada, foi estabelecida uma entidade da sociedade civil, a Associação da Parada do Orgulho GLBT de São Paulo, que, além realizar o evento em junho, atua em diversas frentes no resto do ano, como: registro, acolhimento e encaminhamento de casos de discriminação e violência; mobilização social por direitos, legislação e políticas públicas em prol dos homossexuais; entre outras.

Acompanhando o aumento no número de participantes, tem-se registrado um crescimento em relevância política e reconhecimento social das Paradas em todas as partes do mundo. Como afirma Machado, "as 'Paradas Gays' têm se revelado uma importante ação coletiva de cunho político, e instrumento de participação social e política de Gays, Lésbicas, Bissexuais, Travestis e Transgêneros, na sociedade contemporânea" (2007, p.6). Porém, de acordo com que o fenômeno das Paradas ia se expandindo, foram surgindo as críticas quanto ao caráter festivo e carnavalesco do evento.

As Paradas, onde quer que aconteçam, são marcadas pelo aspecto lúdico: música alta, pessoas fantasiadas, looks inusitados, paqueras generalizadas, extravagantes drag queens, imagens multicoloridas. Ao adquirir uma conotação massiva, passou-se a questionar a motivação dos participantes das Paradas. Diversos ativistas começaram a demonstrar seus "receios quanto a uma possível despolitização do movimento homossexual (...) [e] quanto a Parada se tornar um momento meramente festivo, perdendo de vista suas possibilidades de impacto social” (MACHADO, 2007, p. 10). Tais críticas costumam dicotomizar as possibilidades de motivação, acreditando que o aspecto lúdico esvazia o político ${ }^{14}$.

\footnotetext{
13 Disponível em https://pt.wikipedia.org/wiki/Parada do orgulho LGBT de São Paulo. Acesso em 25/07/2007.

14 “O jornalista Jardel Teixeira, 45, já foi duas vezes ao evento 'para acompanhar amigos', mas não o frequenta mais porque acha que ele se transformou em 'festa'. 'A parada não é uma manifestação política
} 
Até mesmo uma pesquisa feita com participantes da $10^{\circ}$ Parada do Orgulho GLBT de São Paulo - 2006 colocou tal preocupação em pauta. Quando questionados sobre o principal motivo de terem ido a Parada, 50\% dos entrevistados apontaram motivos lúdicos (“curiosidade", "diversão", "paquera”) e 47\% engajamento social ou político ("para que os homossexuais tenham mais direitos no Brasil", "solidariedade com amigos ou parentes homossexuais", "por ser simpatizante das reivindicações do movimento GLBT") (FACCHINI \& FRANÇA \& VENTURI, 2007, p. 45).

Uma outra crítica acompanha a primeira. Para muitos, o evento e, principalmente, sua cobertura midiática enaltecem caricaturas e estereótipos do homossexual. O resultado seria o reforço de estigmas em torno da população transexual, travesti, gay, lésbica e bissexual, quando o propósito da Parada seria justamente negá-los. Novamente cabe retomarmos algumas reflexões que Bakhtin faz sobre a dinâmica própria dos signos sociais: "o ser, refletido no signo, não apenas nele se reflete, mas também se refrata" (1987, p. 46). Quando indivíduos historicamente estigmatizados se propõem a participar de uma enunciação coletiva cujo auditório social se encontra carregado de estereótipos a eles direcionados, inevitavelmente estarão sujeitos à refração de suas intenções. Vale lembrar que, como nos fala Bakhtin, a compreensão é necessariamente ativa e implica a utilização de pressupostos que parcialmente negarão e afirmarão o signo posto no jogo da enunciação. Na batalha pelo deslocamento do significado, os enunciadores encontrarão sempre o ambiente hostil da ideologia que procura paralisar os sentidos e torná-los válido para toda a sociedade. Quando as câmeras de televisão ou lentes fotográficas procuram ávidas os personagens mais pitorescos que participam das Paradas, na verdade buscam reflexos exteriores das imagens que foram socialmente construídas em torno dos homossexuais. Mas em tal busca também se traem: o signo refletido forçosamente altera seu espelho, com maior ou menor intensidade. O importante é termos em mente que a negociação do sentido nunca cessa: e é no jogo da enunciação que se intensifica.

e social como deveria ser. O rumo da coisa se perdeu. O propósito da parada deveria ser outro e não um desfile de carnaval, porque é isso que acontece. Uma manifestação é algo bem diferente de encher trios elétricos com homens bonitos, músicas para as pessoas dançarem, beberem e se divertirem', critica." Disponível em http://www.acapa.com.br/site/noticia.asp?codigo=2093. Acesso em 26/07/2007. 
Em se tratando da crítica ao tom festivo das Paradas, não nos parece fortuito que o espírito carnavalesco acompanhe a marcha dos homossexuais por entre os caminhos urbanos desbravados pelas Paradas. Para pensarmos tal relação, vamos nos valer de um texto escrito por Bakhtin em 1940, Cultura Popular na Idade Média, em que o autor analisa o carnaval na Idade Média e o sistema de imagens da cultura cômica popular da época. Mas é importante tecer uma ressalva antes de fazer uso de determinados conceitos do texto: para Bakhtin, o contexto é essencial para pensar qualquer realidade. Quando o autor analisa a cultura popular na Idade Média encontra o carnaval embrenhando todas as "formas fundamentais de expressão da sensação popular do mundo" (BAKHTIN, 1993, p. 5), devido ao específico contexto político-social e a importância que o carnaval tinha para a sociedade da época. Tais manifestações carnavalescas e uma certa concepção estética que caracterizava a cultura popular da época pertencem a um contexto específico e precisam ser tomados de empréstimo com cuidado quando aplicados a outro objeto de análise. De qualquer forma, Bakhtin afirma que o próprio "princípio da festa popular do carnaval é indestrutível” (BAKHTIN, 1993, p. 30) e, por isso acompanha(rá) a própria trajetória humana. Durante o carnaval, seus participantes experimentam o

triunfo de uma espécie de libertação temporária da verdade dominante e do regime vigente, de abolição provisória de todas as relações hierárquicas, privilégios, regras e tabus (...) [além do] contato livre e familiar entre indivíduos normalmente separados na vida cotidiana pelas barreiras intransponíveis da sua condição, sua fortuna, seu emprego, idade e situação familiar" (id., p. 9).

Na Parada do Orgulho Gay, os participantes gozam a possibilidade temporária de viver sua orientação sexual publicamente. Jovens e velhos, homens e mulheres, ricos e pobres, brancos e negros, se misturam e celebram a diversidade sexual longe dos riscos cotidianos da homofobia e da discriminação. A alegria e o riso que tomam conto do evento talvez se devam mesmo a esse caráter de celebração da liberdade dos padrões ditados pela "normalidade". Quando o espírito carnavalesco toma a Parada, “ajuda a liberar-se do ponto de vista dominante sobre o mundo, de todas as convenções e de elementos banais e habituais, comumente admitidos (...) permite compreender a possibilidade de uma ordem totalmente diferente do mundo" (BAKHTIN, 1993, p. 30): de verdadeiro respeito à diversidade sexual, de tolerância e respeito entre diferentes formas de ver e viver a 
experiência de estar no mundo. É importante notar que Bakhtin enxerga a própria festividade, em qualquer de suas vertentes, como uma "forma primordial, marcante, da civilização humana" onde se exprime uma determinada concepção de mundo: "o riso e a visão carnavalesca do mundo (...) destroem (...) as pretensões de significação incondicional e intemporal, liberam a consciência, o pensamento e a imaginação humana, que ficam assim disponíveis para o desenvolvimento de novas possibilidades" (BAKHTIN, 1993, p. 43, grifo meu).

Motivações diversas arrastam cada um dos integrantes da multidão que participa da Parada. Mas, além de sua simples presença compor uma ação coletiva que "questiona as posições institucionais de legitimação do silenciamento da homossexualidade" (MACHADO \& PRADO, 2007, p. 12), o espírito carnavalesco que o anima é o mesmo que ri de uma verdade única e aponta "para um futuro ainda incompleto" (id., p. 9).

\section{Conclusão}

Por fim, cabe levantarmos aqui um conceito muito caro e que perpassa toda a reflexão ontológica bakhtiniana: o de responsabilidade/respondibilidade. Para Bakhtin, estar no mundo é agir no mundo: "atuo mediante o ato, a palavra, o pensamento, o sentimento; vivo, venho a ser através do ato" (BAKHTIN, 1992, p. 154). A atitude, além de requerer uma posição de valores, demanda também, e antes de qualquer coisa, responsabilidade. A abertura à experiência de estar no mundo, do lugar único que somente eu posso ocupar, exige de mim "respondibilidade": capacidade de responder por cada um dos meus atos dentro do ato maior que é minha vida. Por ser o que sou, viver o que vivi, terei de responder pela limitada (falta), mas absolutamente singular (excesso) parcela da verdade reservada a minha existência. "Um ser humano não tem direito a um álibi - a uma evasão dessa responsabilidade única que é constituída pela sua atualização de seu 'lugar' único, irrepetível no Ser, ele não tem direito a uma evasão desse único 'ato ou ação responsável' que toda a sua vida constitui"' (BAKHTIN, 1993, p. 16, grifo meu). Responderei com minha própria vida pela dádiva e a miséria de ser o que sou no mundo.

Porém "é na medida que tenho direito de participar no mundo da alteridade que sou passivamente ativo nele" (BAKHTIN, 1992, p. 150). Minha ação é constituinte da 
experiência do mundo quando tenho outorgado o direito de trocar, dialogar com o outro. E tal direito não conquisto, nem dele faço uso, sozinho: necessito do outro para ativá-lo.

Que tomar parte no mundo da alteridade seja também assumir a responsabilidade ética de responder de forma conjunta contra todas as formas de desrespeito a liberdade e a dignidade humana. De cada um dos atos de reivindicação dos direitos dos transexuais, gays, lésbicas, bissexuais e travestis deve também ecoar as vozes de milhões de outras subjetividades oprimidas pela estupidez de qualquer outra pretensão a verdade única. Talvez a etapa seguinte, ou melhor, o passo a ser dado simultaneamente a qualquer etapa, seja o de derrubar fronteiras reivindicatórias e, através do diálogo, estabelecer metas comuns e lutar para que a verdade seja tão multicolorida quanto um arco-íris: com suas infinitas novas cores subjacentes da mistura das anteriores. Não se pretende a busca da fusão de valores entre subjetividades que invariavelmente ocupam lugares distintos no evento do mundo. Nem a concordância de suas cosmovisões. Tampouco a utopia de uma convivência harmônica (isso é impossível se pensarmos que cada subjetividade nunca coincide com sua atualidade, que seu valor é sempre um porvir). Importa aqui resgatar as possibilidades do diálogo, da troca, da mútua exposição de valores e a necessidade condicionante de que tais posições estejam em planos axiológicos equivalentes.

\section{Referências}

BAKHTIN, Mikhail. Cultura Popular na Idade Média e no Renascimento: o contexto de François Rabelais. São Paulo: Hucitec, 1993

, Mikhail. Toward a philosophy of act. Austin: University of Texas Press, 1993.

, Mikhail. Estética da Criação Verbal. São Paulo: Martins Fontes, 1992.

, Mikhail. Questões de literatura e estética. São Paulo: Hucitec, 1990.

, Mikhail.[Volochnov]. Marxismo e Filosofia da Linguagem. São Paulo: Hucitec, 1987.

, Mikhail. Problemas da poética de Dostoievski. Rio de Janeiro: Forense Univ., 1981.

FACCHINI, Regina; FRANÇA, Isadora L.; VENTURI, Gustavo. Sexualidade, cidadania e homofobia: pesquisa $10^{\mathrm{a}}$ Parada do Orgulho GLBT de São Paulo - 2006. São Paulo: APOGLBT, 2007. Disponível em: http://www.paradasp.org.br/download/Livrojunho07.zip, consultado em 25/07/2007.

MACHADO, Frederico V.; PRADO, Marco Aurélio M. Visibilidade, Sexualidade e Cidadania na Parada do Orgulho GLBT de Belo Horizonte. Disponível em http://www.sociologia.ufsc.br/npms/frederico_viana.pdf, consultado em 24/07/2007 
SILVA, Hélio R.S. Travesti: a invenção do feminino. Rio de Janeiro: Relume-Dumará/ISER, 1993.

SILVA, Rose \& ACKERMANN, Luciana. A estupidez da intolerância. Revista Fórum, no 3, 2002. 